\title{
Urban Heritage and Tourism in the Gulf: The Case of Dubai in the UAE
}

\author{
Djamel Boussaa \\ Qatar University, Doha, Qatar
}

\begin{abstract}
Heritage and tourism have become dynamic areas of development in the world during the last two decades. The idea of heritage is crucial to the critical decision-making process as to how irreplaceable resources are to be utilized by people of the present or conserved for future generations in a fast-changing world. In view of the importance of "heritage" to the development of a tourist destination, the emphasis on developing appropriate adaptive reuse strategies cannot be overemphasized. In October 1999, the 12th General Assembly of the International Council on Monuments and Sites (ICOMOS) in Mexico stated that in the context of sustainable development, two interrelated issues need urgent attention: cultural tourism and historic cities. The two issues underscore the fact that historic resources are non-renewable, belonging to all of humanity. Without adequate adaptive reuse actions to ensure a sustainable future for these historic resources, this may lead to their complete vanishing. The Gulf rich urban heritage is now being recognized as a valuable resource for future development. This paper focuses on the role of heritage tourism and its implications for urban conservation in the context of old Dubai, UAE. Therefore, in order to use heritage wisely, it will be necessary to position heritage as an essential element of sustainable development, paying particular attention to heritage tourism. The question to be raised here is: "How can urban heritage be used wisely for tourism without compromising its educational and social roles in enhancing the local cultural identity?”.
\end{abstract}

Keywords: tourism, heritage, adaptive reuse, sustainable development, historic cities, Dubai

\section{Introduction}

Recently, a new mode of development emerged in a way to reuse and develop historic cities and districts for tourism. To achieve this, there is a need to make funds available by developing heritage attractions for tourism. Many heritage sites are being compromised, because local authorities are not aware of the value for conserving them. Developing historic areas for tourism and commerce requires the transformation of conservation from a political, cultural, and social aspect to that of economic development.

The financial input that tourism can deliver to host communities can be the incentive for conservation work. Besides housing and other activities, heritage tourism can be a major catalyst of sustainable development, for historic centers like the Kasbah of Algiers in Algeria and Dubai. Overemphasis on the tourist function creates pressures for new services and associated development, sometimes to the detriment of the local population and can lead to the damage of significant cultural assets. Therefore, tourism development needs to be carefully managed and controlled. Furthermore, there is a need to avoid the expansion of inauthentic structures, which can further erode the character of the historic center that visitors have come to visit.

Djamel Boussaa, assistant professor, College of Engineering, Department of Artchitecture and Urban Planning, Qatar University. Email: DjamelB60@Gmail.com; DjamelB60@qu.edu.qa. 
Tourism is encouraged by governments in order to obtain foreign currency. However, over-promotion of tourism can be disastrous; it can destroy the culture and the environment that people came to enjoy. Tourists do not leave a city untouched by their presence. The tourist, through his/her demands, subtly and sometimes drastically changes the character of a place. Residents in most cities want tourists for economic reasons and will change their cities and lives to serve them (Appleyard, 1979).

The merit of social intercourse between tourists and local residents as a way towards fostering better understanding and good will among nations is a major benefit gained from tourism. Whilst this can be possible in countries where the flux of tourists is comparatively acceptable, however, in cases of mass tourism, tourist's tastes and habits have proofed to be offensive to the local population in many circumstances.

Many of the other socio-cultural problems linked to tourism are related to the degree of intensity of tourism development. While it is difficult to measure, there is a relationship between tourism density and the growth of local resentment towards tourism. The flow of tourists into a region increases the densities at which people live and overcrowds the facilities which tourists share with the local population. Therefore, overcrowding can reduce the value of the holiday experience while creating additional strains for the host community.

The impact of tourists can be substantial in terms of environmental change. At destination areas, tourism may involve a physical transformation through hotel and infrastructure development. Tourists need hotels; usually, tourists prefer to stay in modern comfort, close to the center and with a view on the historic city from the bedroom window. The result is predictable: In many historic cities, new hotels have sprung up adjacent to the historic districts. A similar case can be found in old Dubai, such as Fareej (district) Al Fahidi in Bur Dubai and the Deira side. The skylines of these historic areas are surrounded and hidden by the mushrooming of adjacent high-rise modern hotels and multi-use tower blocks that sprang around them.

\section{Heritage Tourism in Dubai}

Dubai, the second largest city in the UAE, is the most cosmopolitan and economically open city in the Gulf; it is less oil-dependent than the capital Abu Dhabi. Dubai is located at the crossroads of ancient Arabian trade routes midway between Europe and the Far East. The emirate lies on an area of 3,885 $\mathrm{km}^{2}$, corresponding to 5\% of the UAE; the present population numbers a total of 2,269,000 people as of October 2014 (see Figure 1). ${ }^{1}$

The philosophy of the emirate in the future is to diversify its economic base away from the dependency on oil and try to explore its talent as a merchant and entrepreneurial city. The amount of revenues generated by oil is shrinking and represents only $18 \%$ of its total income. It is believed that tourism is well placed to take over from oil as the main economic source of income in the coming years (Darke, 1998). Comparatively speaking to other cities of the region, Dubai is well equipped with hotel infrastructure and entertaining and shopping facilities to host a large number of tourists.

Since January 1997 when the Department of Tourism and Commerce Marketing (DTCM) took over from the Tourism and Trade Promotion Council, there has been a renewed focus on promoting Dubai as an ideal tourist destination. In 2011, Dubai had 575 hotels and hotel apartments with a total of 74,843 rooms at an average occupancy of $74 \%$. During the same year, the number of tourists who spent nights in these hotels reached 9,095,570, while the hotel revenues reached 15,965,011 thousand Dirhams. ${ }^{2}$

\footnotetext{
1 Retrieved from http://www.dsc.gov.ae.

${ }^{2}$ Retrieved from http://www.dubaitourism.ae.
} 


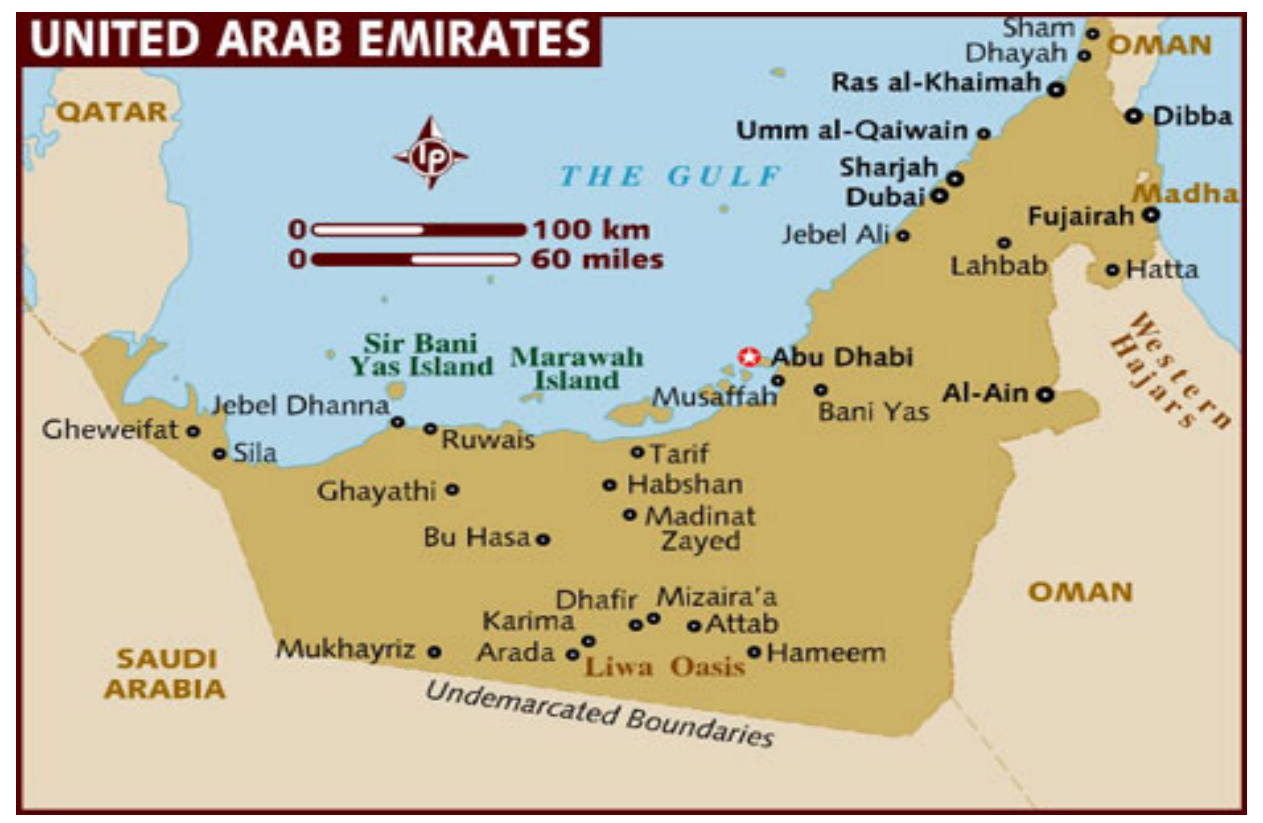

Figure 1. The location of the UAE and the emirate of Dubai.

Source: Retrieved from http://www.lonelyplanet.com/maps/middle-east/united-arab-emirates/.

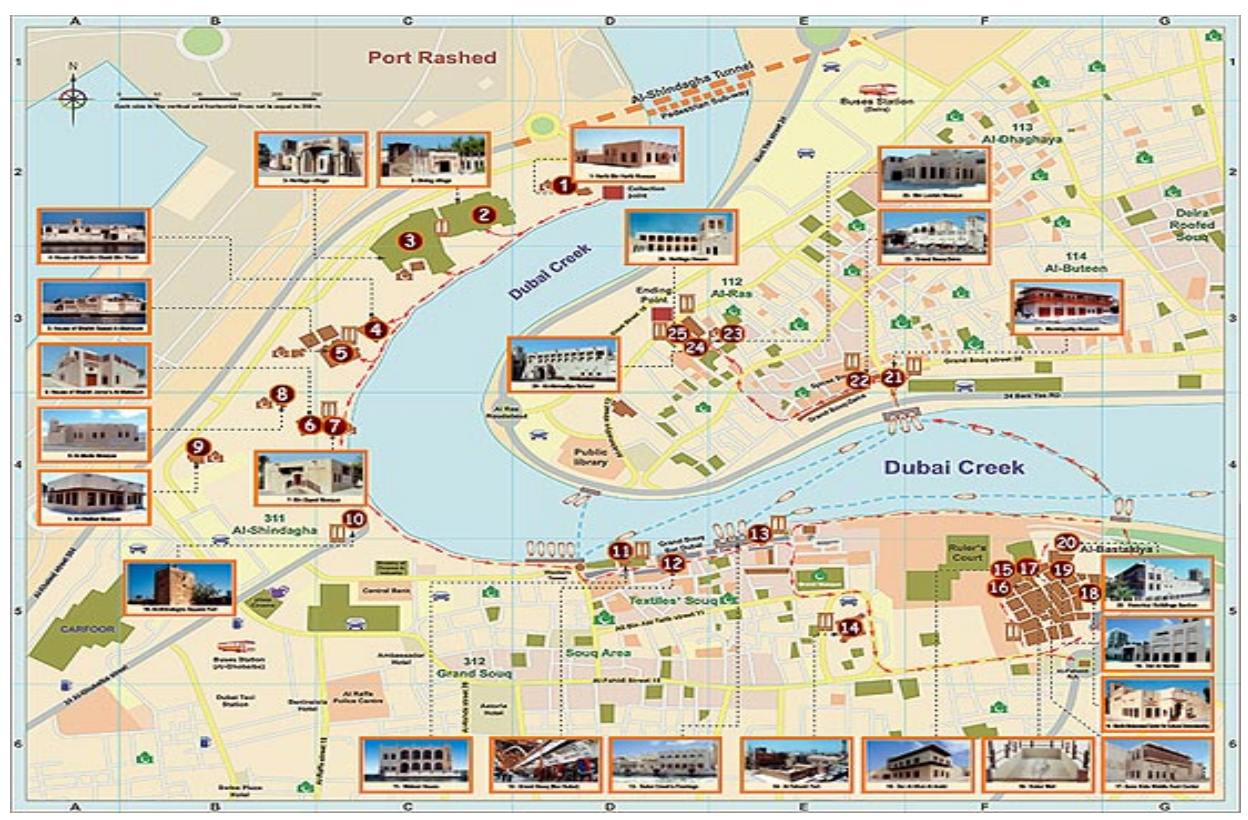

Figure 2. The historic center of Dubai with the main heritage attractions (Courtesy of Dubai Municipality, historical buildings section).

With the exception of the traditional mountainous Hatta village, Dubai is a semi-desert, with one of the most spectacular harbours in the region. The Dubai Creek, called locally “Khor Dubai”, $10 \mathrm{~km}$ long, divides the city into two parts. The southern side is called Bur Dubai, which comprises three main historic districts, Shindagha, Old Deira, and Bur Dubai. The northern part known as Deidra includes the old Deidra, the new central business district, and the international airport. Al Maktoum and Al Garhood bridges, along with the Shindagha subway, link the two parts of the city. Al Abra (dhow), the traditional dhow crossing through the creek is still largely used to commute between the two banks of the creek, Bur Dubai and Deira (see Figure 2). 
The rapid growth in the years following the formation of the UAE in 1971 turned Dubai into a vast building site. Roads, power supplies, telephones, streetlights, and drainage were laid within decades. While this rapid development, the well-being of people improved, on the way it sacrificed many significant chapters of its urban heritage. The latter was threatened of complete extinction, due to the rapid development and urbanisation that emerged after the discovery of oil in 1966 and the beginning of its exportation in 1969. The rapid urban development that followed oil discovery threatened, during the 1970s, the historic center of Dubai of complete extinction. Today, the old core survives as disparate small parts in the city; only 371 historic buildings have survived from an original number of 3,000 (Boussaa, 2003).

In Dubai, as elsewhere in the UAE and the Gulf, urban conservation has enlarged from an initial concern with the protection of individual buildings and monuments to the conservation of groups of buildings and areas. During the last decade, heritage conservation has been increasingly seen as a valuable policy instrument in helping to regenerate old Dubai. This trend has become synonymous with urban revival, since conservation of the urban heritage can help fulfill economic objectives as well as respond to the local social and cultural needs. $\mathrm{Al}$ Shindagha and $\mathrm{Al}$ Fahidi are two interesting examples in the heart of Dubai.

In order to enhance the tourist visitation in the city, it may be appropriate to propose an interesting tour that starts from Al Fahidi Fort, the oldest building erected in 1799 to reach the first Dubai Municipality built in 1950 in Deira (see Figure 3). This will give the visitor an opportunity to observe the city's development through history. After years of neglect and marginalisation, the Shindagha heritage area is being revitalized to become an attractive traditional tourist quarter.

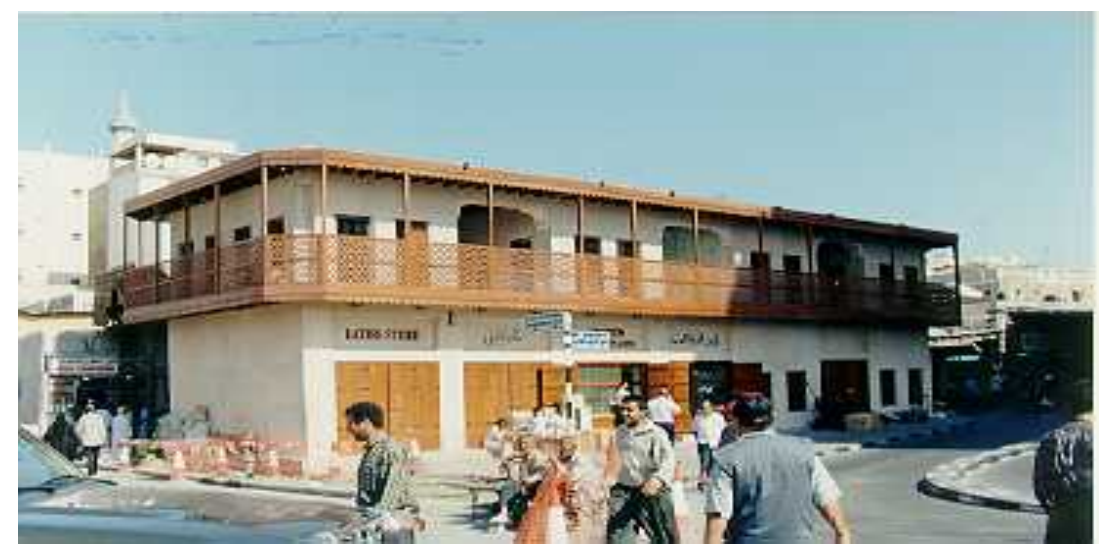

Figure 3. The old Dubai Municipality building built in 1950. Source: The author.

\section{Revitalization of the Shindagha Heritage Area}

The original site of the Ruling Family, Al Maktoum, was the Shindagha district, situated in the mouth of the creek, which was developed around the Sheikh Saeed's house, built in 1896. Around 1958, when the Ruler's palace was moved out from Shindagha to Zaabil, the area was abandoned and was left to decay and was vanishing slowly. Furthermore, The Shindagha area was completely swept away after a decision had been taken by the Dubai authorities in 1991 to launch a vast high-rise development, similar to that of the Deira side (see Figure 4). However, the restoration of Beit Sheikh Saeed and its accompanying conservation awareness, which was well publicized through media, conferences, and newspapers, encouraged the local authorities to review their earlier decision and opted finally to develop the whole area for tourism (Hadjri \& Boussaa, 2007). 
The revitalization project of the historic Shindagha area goes back to March 1996. The project aimed at retracing the history of Dubai through the establishment of a tourist heritage village along the creek. The village is composed of two main zones: a marine heritage zone, with the Diving Village as its center point and the Heritage Village, where the restored Ruler's residence Beit Sheikh Said al Maktoum is located. In addition to the two heritage villages, a long pedestrian walk has been proposed along the creek (see Figures 5 and 6). The latter starts from the Shindagha fort and ends at the creek entrance. Many gathering places and activities areas have been established between the two ends of the walk (Dubai Municipality, 1996-1997).

These meeting points near the Diving Village, Beit Seikh Saeed, and the Heritage Village are to be used for folklore activities. With the wise integration of appropriate lighting to enhance the traditional image of the area, the whole surroundings have become an important attraction place for tourists and local visitors. The construction work lasted one year, and the two heritage villages were opened for public in March 1997, coinciding thus with the opening ceremony of the Dubai Shopping Festival. Since then, it has become the main hub of heritage and folklore activities, which are performed during the annual Dubai Shopping Festival.

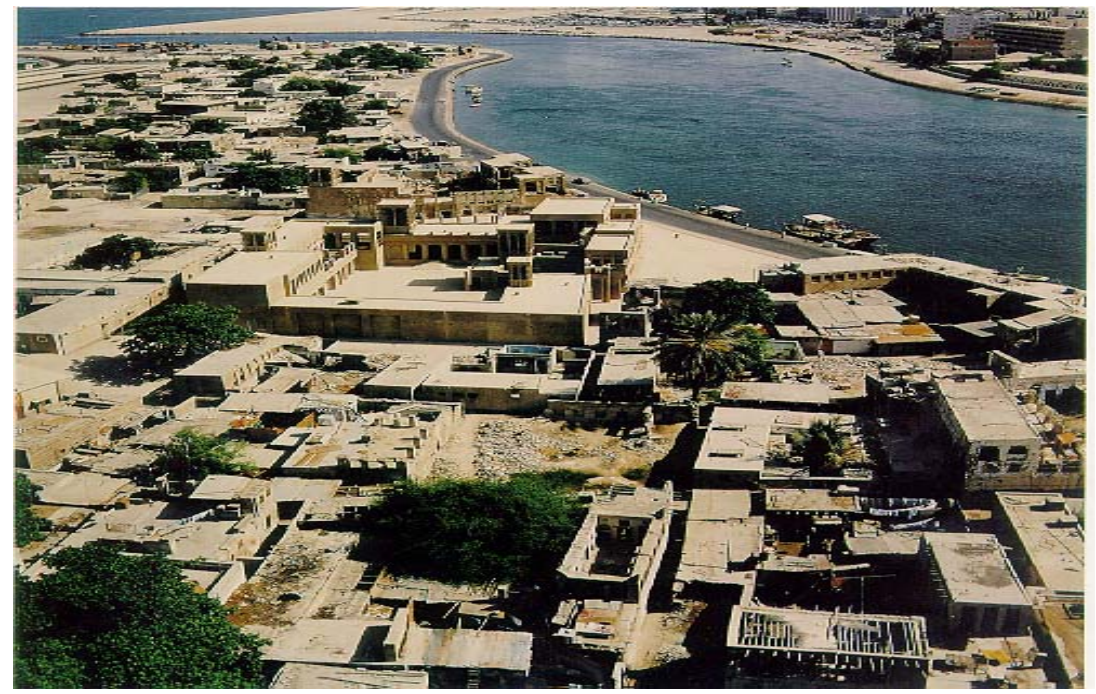

Figure 4. Fareej Al Shindagha, before its demolition in 1991 (Kay, 1991).

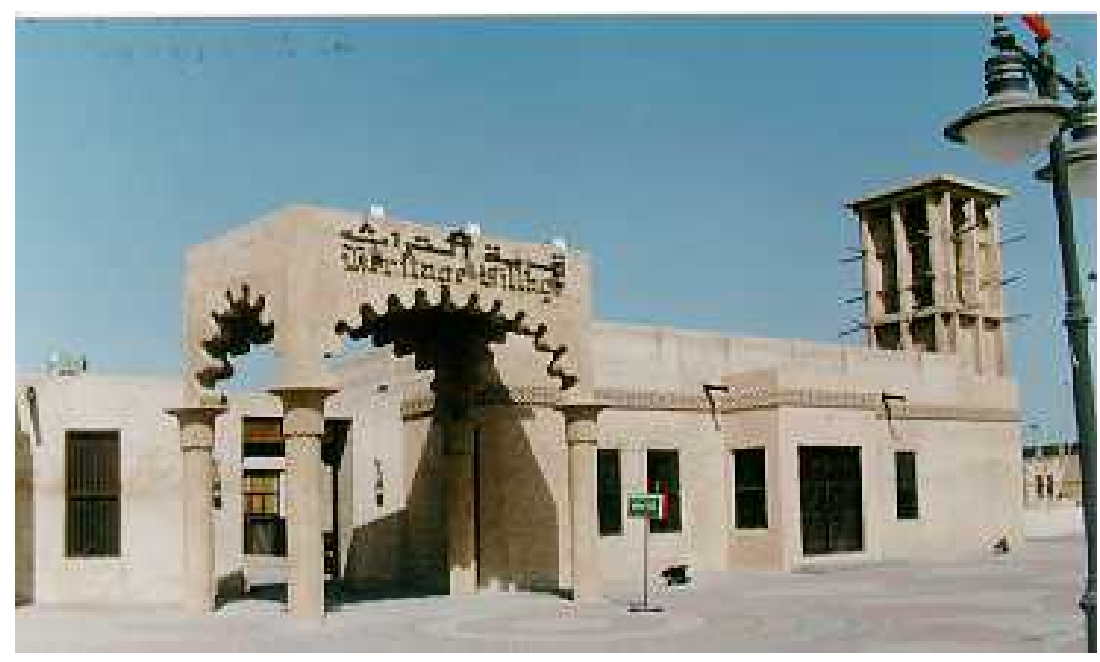

Figure 5. The Heritage Village of Shindagha. Source: The author. 


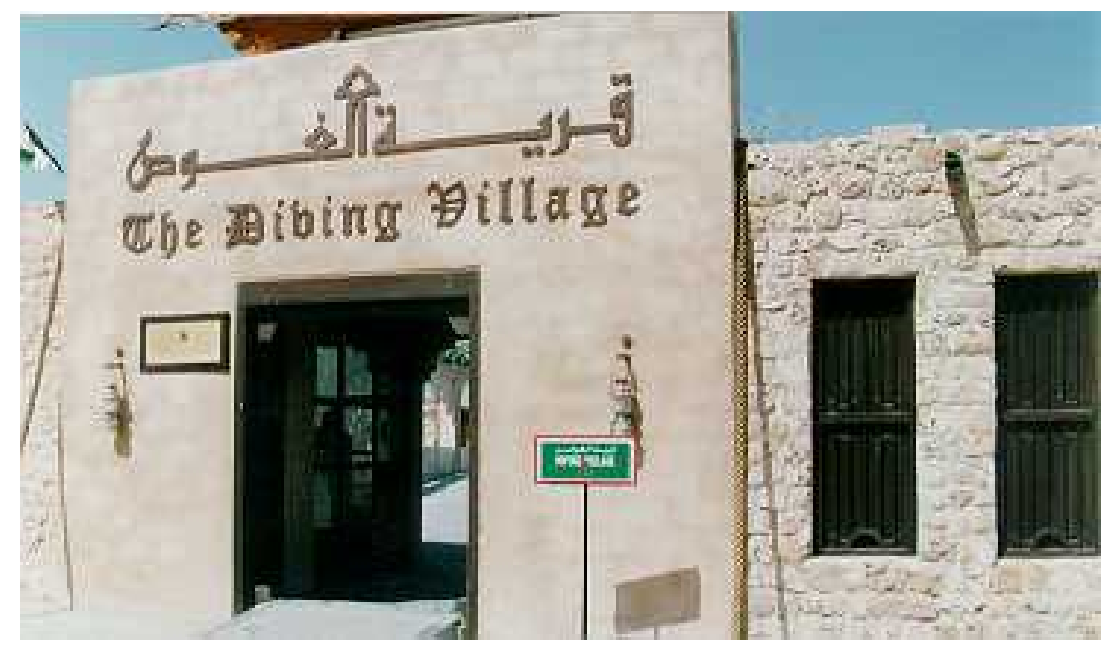

Figure 6. The Diving Village of Shindagha. Source: The author.

Al Fahidi District, From Survival to Revival

Al Fahidi (previously Al Bastakia) district in Bur Dubai is located on the eastern part of the historical town. The district lies on an area of $300 \mathrm{~m}$ along the creek with a depth of $200 \mathrm{~m}$ to the south. This part of the city reflects an important era of the city's urban development. This historical district is an expression of a way of life that is fast disappearing. Al Fahidi provides a record of the social history of the first half of the 20th century, the period (1890-1955) when Dubai emerged to be the chief commercial center in the Gulf.

Al Fahidi is a unique survivor of old Dubai; only 25 wind-tower houses have survived out of the 200 dwellings originally built. Due to overpopulation of the area, there were usually 100 low-income workers inhabiting one house, coupled with a poor maintenance, their decline accelerated during the 1970s and 1980s, which rendered the quarter to look like a slum. While this district was under a continuous threat of demolition, an appeal was made in 1975 to save at least one house in Al Fahidi (Coles \& Jackson, 1975):

It is hoped that it may be possible to make a fuller record of the whole Bastakia before it is too late, and there are strong arguments for retaining at least one house as a folk museum. In the mean time, we hope that this portrait of a house will serve to arouse an interest in and an appreciation of the traditional buildings in the area. (p. 85)

Following this appeal, and since the early 1980s, the city of Dubai has been striving to save the few remaining historical relics. One of the first priorities of Dubai Municipality was the conservation of Al Fahidi. The restoration of the wind-tower houses, with the intention of their adaptive reuse for tourism, was a major goal to achieve. Recently, many restored houses have been reused to accommodate a small hotel, shops, museums, and restaurants. This can help revive the fareej (district) by keeping it alive during day and night. However, housing remains a major catalyst in providing a sustainable life in this old district, while preserving the original identity of the quarter (see Figure 7).

Heritage tourism in Dubai is growing rapidly. A survey conducted by the municipality in 1994 concluded that tourists who visited Al Fahidi included people who spent a whole day exploring the old houses, to coach loads of beach hotel visitors passing half an hour there on their way to Bur Dubai and Deira souks. In 1994, the estimate number of visitors was around 10-15,000 visitors/year, spending an average of 15-20 minutes in Al Fahidi. At that time, and before the rehabilitation work started, the Majlis Gallery was the only tourist attraction available, while no hotels for tourists were available. 


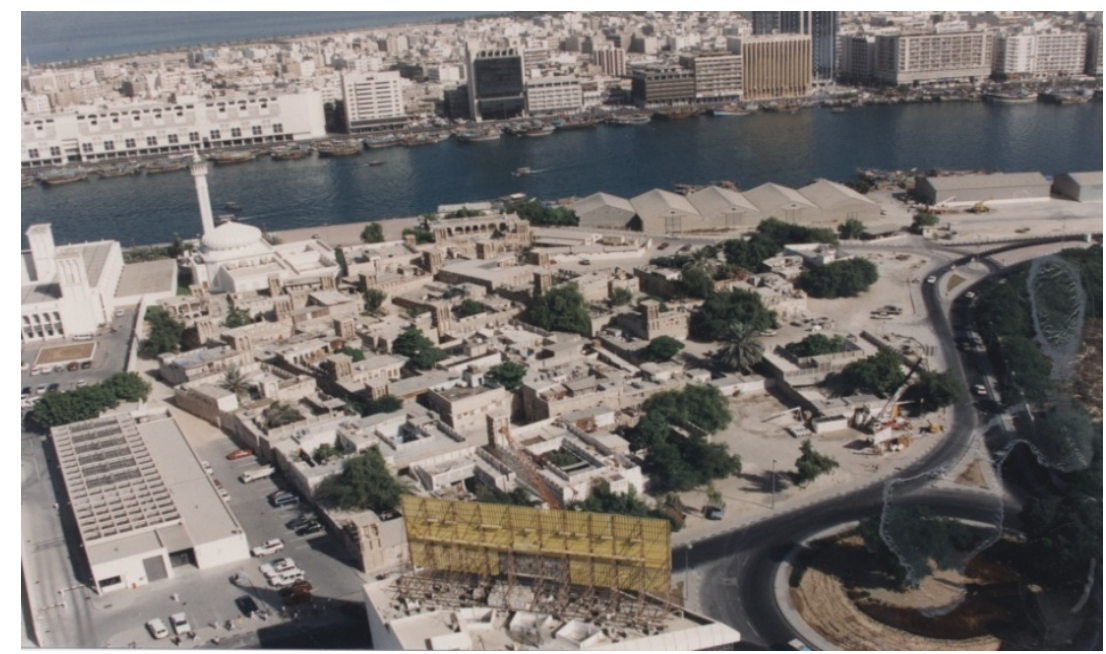

Figure 7. An aerial view of Al Fahidi in 1994 before its conservation (Gray, 1995).

Llelwyn Davies Consultants proposed creating a group of attractions that would add up to a half-day's visit for tourists, supported by places to spend time and money such as cafes, restaurants, shops, galleries, and museums. Heritage and cultural activities are closely bound up with tourism, and all of them can bring life and economic value to the area. However, such activities could risk ruining the area if a mass tourism approach was applied, whereas if soft tourism strategy was chosen, such activities could contribute to the revival of Al Fahidi.

The Dubai Shopping Festival is one of the world's largest family festivals. Every year, since its launch in 1996, this event has attracted millions of people around the world, a large portion of this number take the opportunity to visit the heritage sites. During these festivals, a number of major venues are designated ranging from the Global Village to other sports and recreational venues. The Heritage Village and Bait Sheikh Saeed in the historic district of Shindagha, and Fareej Al Al Fahidi are considered as the main heritage venues of the festival.

This annual event has injected a new life in the once forgotten old Dubai. Today, it attracts many tourists and local visitors to Bait Sheikh Saeed and the surrounding heritage and diving villages, as well as Al Fahidi. The latter might have been a great incentive for Dubai authorities to launch a new program of reconstructing another 30 traditional dwellings in Shindagha to make the whole area an integrated heritage quarter (see Figure 8).

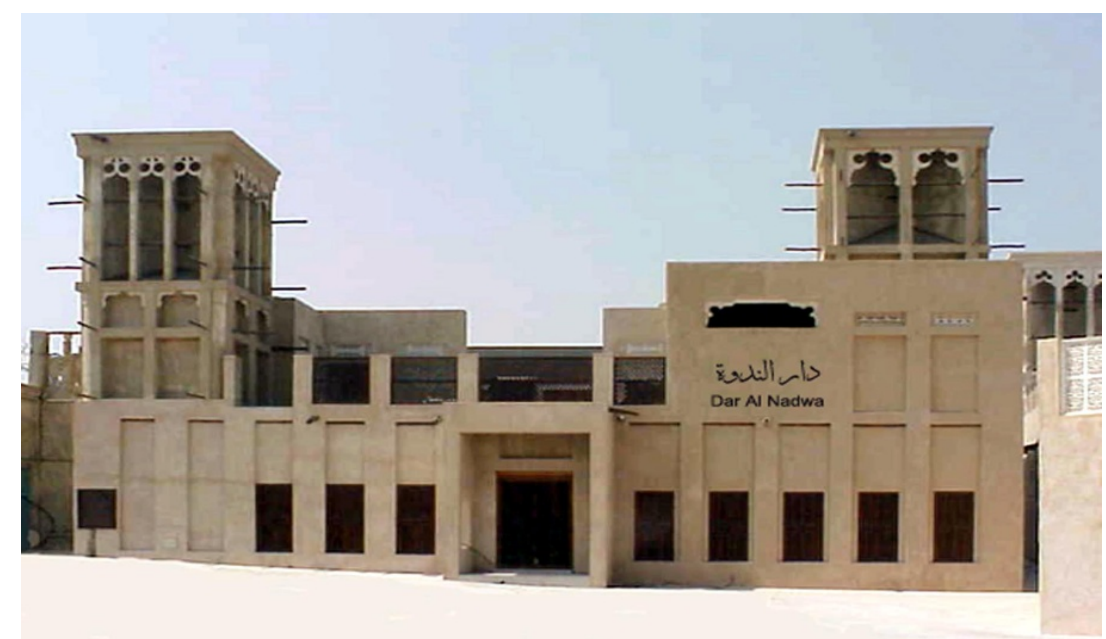

Figure 8. View of Dar Enadwa; A rehabilitated house in Al Fahidi district. Source: The author. 


\section{Conclusions}

In the historic center of Dubai in particular and the Gulf in general, a total preservation should not be the panacea. Where needed, some change of use may be introduced, and that should be on a small scale. Since very few heritage buildings have survived, demolition should be avoided whenever possible, and should normally be chosen as a solution only for unsound buildings.

It is well known that inhabitants are the catalyst of urban life in the city. They create and constitute the socio-cultural and economic systems, which bring life to the built environment. It is, therefore, necessary to revitalize these historic cities. This should be done by conserving whole areas such as Al Fahidi and Al Shindagha together with the social life that ensures their livability and sustainability.

Urban conservation does not necessarily mean preserving a building but reviving its spirit and life. It means being flexible enough to adapt the objectives of rehabilitation to the needs of modern living while respecting the local community values. Rehabilitation of public areas is important and essential as it adds to the quality of a neighborhood and to the way in which people perceive and identify with their locality. It is, therefore, paramount that rehabilitation includes public areas to strengthen people's sense of belonging.

The function of urban conservation for society as a whole should primarily restore a sense of cultural identity. The historic center of Dubai has been fragmented through unwise massive redevelopment. However, there is still a possibility to re-construct the unity of its dislocated urban fabric. A combination of rehabilitation, reconstruction, and new infill projects, which respect the local traditional character, should be developed, to reassemble the surviving fragments of the three quarters, Al Fahidi, Shindagha, and old Deira.

Old Dubai is an interesting case of how tourism can engender conservation efforts. The integration between tourism and conservation enables the critical balance to be maintained between the needs of the resource (conservation) and those of the visitor (tourism). The situation of historic towns in the Gulf is particularly alarming. The historic town is both the content and container, as it were, of heritage. Heritage tourism is an important and desired activity for both visitors and hosts.

Though this interaction is important, the individual character and identity of each city and country should not be submerged and lost. However, heritage tourism should not be developed only for global tourists but must be for the benefit of local people at the first instance. This should help them understand the significance of their urban heritage, thus be aware of the need of conserving it, live within it, and pass it on for future generations.

\section{References}

Appleyard, D. (1979). The conservation of European cities. London: The MIT Press.

Boussaa, D. (2003). Dubai: The search for identity. In G. Moser, E. Pol, Y. Bernard, M. Bonnes, J. A. Corraliza, \& M. V. Giuliani (Eds.), People, places, and sustainability. Seattle, Toronto, Bern, Gottingen: Horace \& Huber.

Coles, A., \& Jackson, P. (1975). A windtower house in Dubai. London: Art and Archeology Research Papers.

Darke, D. (1998). Discovery guide to the United Arab Emirates. London: IMMEL Publishing.

Dubai Municipality. (1996-1997). Planning studies; The Shindagha revitalization project. Dubai: Dubai Municipality.

Gray, S. (1995). Al Bastakia conservation project. Paper presented at the Symposium on Conserving Urban Heritage, Dubai, UAE.

Hadjri, K., \& Boussaa, D. (2007). Architectural and urban conservation in the United Arab Emirates. Open House International, 32(3), 16-26.

Kay, S. (1991). Architectural heritage of the gulf. Dubai, UAE: Motivate Publishing. 